\title{
In vitro methionine supplementation during lipopolysaccharide stimulation modulates immunometabolic gene network expression in isolated polymorphonuclear cells from lactating Holstein cows
}

\author{
M. Vailati-Riboni, ${ }^{1}$ T. Xu, ${ }^{2}$ B. Qadir, ${ }^{3}$ R. Bucktrout, ${ }^{1}$ C. Parys, ${ }^{4}$ and J. J. Loor ${ }^{1 *}$ \\ ${ }^{1}$ Department of Animal Sciences, University of Illinois at Urbana-Champaign, Urbana 61801 \\ 2Joint International Research Laboratory of Agriculture and Agri-product Safety of Ministry of Education of China, Yangzhou University, Yangzhou, \\ People's Republic of China 225009 \\ ${ }^{3}$ Veterinary Division, Kurdistan Regional Government, Sulaymaniyah, Iraq 46001 \\ ${ }^{4}$ Evonik Nutrition and Care GmbH, 63457 Hanau-Wolfgang, Germany
}

\section{ABSTRACT}

Methionine (Met) is one of the 2 most limiting amino acids for milk production in dairy cow diets. The accepted "ideal" ratio of lysine (Lys) to Met (L:M) when formulating diets is 3:1. However, blood from cows fed corn silage-based diets without supplemental rumenprotected Met averages approximately 3.6:1 L:M. Recent in vivo research on cattle immunonutrition has revealed that the immune system could benefit from greater Met supply. To study more closely the effects of different L:M ratios, blood polymorphonuclear cells (PMN) were isolated from 5 Holstein cows in mid-lactation $(238 \pm 20$ d postpartum, $33.8 \pm 3.8 \mathrm{~kg}$ of milk/d; mean $\pm \mathrm{SD})$. The PMN were incubated at 3 different levels of L:M (3.6:1, 2.9:1, or 2.4:1) and stimulated with lipopolysaccharide (LPS) at either 0 or $50 \mu \mathrm{g} /$ $\mathrm{mL}$ for $2 \mathrm{~h}$ at $37^{\circ} \mathrm{C}$. Target genes were associated with cytokines, pathogen recognition, nuclear receptors, killing mechanisms, and Met and glutathione metabolism. Data were subjected to ANOVA using PROC MIXED in SAS, with L:M, LPS, and their interaction as fixed effects. Stimulation with LPS upregulated genes related to cytokines (IL1B, TNF, IL10 and IL6) and nuclear receptors, including nuclear factor kappa B (NFKB1) and glucocorticoid receptor (NR3C1), and downregulated the mRNA abundance of chemokine receptor 1 (CXCR 1), lysozyme $(L Y Z)$ and glutathione reductase $(G S R)$. A linear decrease was observed in the mRNA abundance of TNF when L:M was decreased. A similar response was observed for interleukin-1 receptor-associated kinase 1 (IRAK1) and NFKB1 abundance in cells stimulated with LPS (linear effect). A linear increase

Received September 22, 2018.

Accepted May 14, 2019.

*Corresponding author: jloor@illinois.edu of $L Y Z$ mRNA expression as L:M decreased was detected in unstimulated cells. Furthermore, a decrease in L:M led to a linear decrease of superoxide dismutase 1 (SOD1) mRNA abundance in cells challenged with LPS. Overall, LPS challenge triggered the activation of isolated PMN from mid-lactation cows. However, data suggest the use of a shorter incubation time to capture the peak response and not the resolution of the inflammatory response as in the present study. Our results indicate a possible involvement of Met in modulating PMN inflammatory and oxidative stress status and in helping the resolution of inflammation after initial stimulation.

Key words: PMN, lactating cows, inflammatory response, gene expression

\section{INTRODUCTION}

Methionine (Met) and Lysine (Lys) have been identified most frequently as major limiting essential amino acids (AA) in dairy cattle nutrition (NRC, 2001). Besides being an essential constituent of milk casein and a driver of milk production, availability of Met is important for other biological functions (Loor et al., 2013; Osorio et al., 2013; Du et al., 2018). For example, as a lipotropic agent, Met is directly involved in very low density lipoprotein synthesis via the generation of S-adenosylmethionine, the most important methyl donor (Martinov et al., 2010). Being the only essential sulfur-containing AA, Met acts as the precursor for other sulfur-containing AA such as cysteine and homocysteine (Brosnan and Brosnan, 2006) and as precursor for the synthesis of the major antioxidants glutathione and taurine (Atmaca, 2004).

Not only does the immune system benefit greatly from proper nutrition but, indirectly, proper nutrition will also prepare the cow for periods of stress (Zhu et al., 2019), reducing adverse effects and enhancing re- 
covery from them. In humans, Met, along with several of its metabolites, displays an immunonutritional role; that is, they help support and boost certain activities of the immune system (Grimble and Grimble, 1998; Redmond et al., 1998; Grimble, 2006; Li et al., 2007). Increasing the supply of Met by feeding it in rumenprotected form has shown a positive effect on systemic inflammatory indices and immune function of lactating cows, underscoring the positive effects of this AA reported in humans (Osorio et al., 2013; Zhou et al., 2016b; Batistel et al., 2017, 2018; Vailati-Riboni et al., 2017; Zhou et al., 2018).

Current recommendations for duodenal supply of Lys and Met to maximize milk protein content and yield in established lactation are 7.2 and $2.4 \%$ of MP, respectively, with an "ideal" ratio of 3:1 (L:M; NRC, 2001). This recommendation already decreases the ratio of between 3.6 and 3.8:1 observed in Met-unsupplemented dairy diets based on corn/corn silage and soybeans (Osorio et al., 2013; Zhou et al., 2016b). However, the aforementioned improvements to immune function indices in lactating dairy cows were obtained with ratios of approximately between 2.7 and 2.8:1, surpassing the recommended 3:1.

We hypothesized that a decrease in the L:M ratio by increasing Met supply and holding Lys constant would alter gene networks associated with bactericidal response and killing capacity of the polymorphonuclear cells (PMN; e.g., neutrophils), the first responders to pathogen invasion. The specific objective of the present study was to measure alterations in immune gene network expression in response to different ratios of L:M with or without exogenous lipopolysaccharide (LPS) in PMN from dairy cows. To achieve this, we applied an in vitro assay based on freshly isolated circulating PMN, which we previously validated in dairy calves (Abdelmegeid et al., 2017). To avoid the influence of stressors and endocrine changes peculiar to early lactation, we isolated the cells from mid-lactation Holstein cows.

\section{MATERIALS AND METHODS}

\section{Animal Handling and Blood Sampling}

Five Holstein cows were selected from the University of Illinois Dairy Unit herd. Cows were in mid-lactation $(238 \pm 20$ DIM $)$, had an average daily production in the week of sampling of $33.8 \pm 3.8 \mathrm{~kg}$, and were considered healthy (e.g., absence of clinical scenarios, not treated during the current lactation, and milk SCC $<100,000$ ). Cows were housed in a freestall barn with sand-bedded cubicles and access to a concrete lot, where the feed bunks were located. Cows were fed a corn silage-based TMR diet once a day at $0700 \mathrm{~h}$. Ingredients and nutrient composition of the diet are reported in the supplemental materials (Supplemental Tables S1-S3; https:/ /doi.org/10.3168/jds.2018-15737). Cows were milked 3 times a day at 0500, 1200, and $1900 \mathrm{~h}$. Blood was collected from the jugular vein at $0600 \mathrm{~h}$, before feeding, into Vacutainer tubes (BD Vacutainer, Becton Dickinson and Company, Franklin Lakes, NJ), containing 1.5 $\mathrm{mL}$ of ACD solution A (trisodium citrate, $22.0 \mathrm{~g} / \mathrm{L}$; citric acid, $8.0 \mathrm{~g} / \mathrm{L}$; and dextrose $24.5 \mathrm{~g} / \mathrm{L}$ ). From each animal 15 tubes were collected, for a total of 120 to 150 $\mathrm{mL}$ of blood. Blood was immediately placed on ice and transported to the laboratory for immediate isolation of PMN within 40 min of the time of sampling.

Isolation of PMN. The PMN were isolated based on procedures previously described (Abdelmegeid et al., 2017). The final PMN pellets from the 5 animals were then mixed together to obtain a homogeneous pool. Before incubation, a $50-\mu \mathrm{L}$ aliquot of the PMN pool was incubated for $15 \mathrm{~min}$ on ice with $100 \mu \mathrm{L}$ of the primary antibody CH138A solution (Washington State University, Pullman, WA; $15 \mathrm{ug} / \mathrm{mL}$ in $1 \times$ PBS). The aliquot was then washed twice with $2 \mathrm{~mL} 1 \times$ PBS and incubated for another $15 \mathrm{~min}$ on ice, protected from light, with $50 \mu \mathrm{L}$ of secondary antibody solution PE (Southern Biotech, Birmingham, AL; $4 \mathrm{ug} / \mathrm{mL}$ in $1 \times \mathrm{PBS})$ and $50 \mu \mathrm{L}$ of propidium iodide (PI; Thermo Fisher Scientific, Waltham, MA; $50 \mathrm{ug} / \mathrm{mL})$. Cells were analyzed via flow cytometry (BD LSR II, Becton Dickinson), using PE and PI as markers of PMN and viability, respectively. The PMN purity (cells $\mathrm{PE}^{+}$) and viability (cells $\mathrm{PE}^{+} / \mathrm{PI}^{-}$) were greater than $90 \%$.

Incubation and Treatments. The isolated pool of PMN was diluted to a final concentration of $6 \times 10^{6}$ cells per $\mathrm{mL}$ with warm $\left(37^{\circ} \mathrm{C}\right)$, Met-free incubation medium (RPMI 1640, Gibco, Thermo Fisher) and $8 \%$ fetal bovine serum (Sigma-Aldrich, St. Louis, MO) previously heat-inactivated. From the diluted pool, aliquots of 1 $\mathrm{mL}$ were incubated in 14-mL Falcon tubes (Thermo Fisher) with a snap cap design to allow air flow, and allocated to each experimental group. The PMN were assigned to 1 of 3 treatments based on the ratio of Lys to Met, as follows: 3.6:1, 2.9:1, or 2.4:1, calculated based on medium concentration of Lys. The basal ratio of 3.6:1 was chosen based on available plasma AA data from lactating dairy cows (Verbeke et al., 1972; Rogers et al., 1987; Zhou et al., 2016a; Sadri et al., 2017; Marczuk et al., 2018). Actual levels of the 2 AA in the medium were $40 \mathrm{mg} / \mathrm{L}$ for Lys in all treatment groups, and $11.11,13.79$, and $16.67 \mathrm{mg} / \mathrm{L}$ of methionine for the $3.6: 1,2.9: 1$, and $2.4: 1$ groups, respectively. These amounts were, on average, 4 times larger than those 
observed in vivo (e.g., 2.62 and $9.56 \mathrm{mg} / \mathrm{L}$ Met and Lys, respectively; Verbeke et al., 1972; Rogers et al., 1987; Zhou et al., 2016a; Sadri et al., 2017; Marczuk et al., 2018). Each treatment was stimulated with LPS at either 0 or $50 \mu \mathrm{g} / \mathrm{mL}$. Final combination of L:M and LPS were incubated in triplicate. Both Met and LPS (both from Sigma-Aldrich) were added to the test tubes from stock solution previously prepared, using the incubation medium as a diluent. Incubations lasted $2 \mathrm{~h}$ at $37^{\circ} \mathrm{C}$ in a sterile incubator with a controlled $\mathrm{CO}_{2}$ (5\%) atmosphere.

RNA Extraction. After incubation, PMN were pelleted by centrifugation and the supernatant decanted. Total RNA was extracted using Qiazol reagent (Qiagen, Hilden, Germany). The cell pellet was placed in $1 \mathrm{~mL}$ of Qiazol, and tissue was homogenized with a Bead Beater 16 (Biospec Products, Bartlesville, OK) using 2 30-s cycles of the homogenizer at full speed, and placed on ice after homogenization for 1 minute. Homogenized samples were centrifuged to remove any remaining cell debris. Chloroform was then added to the homogenized sample, which was centrifuged at $16,000 \times \mathrm{g}$ for $15 \mathrm{~min}$, at $4^{\circ} \mathrm{C}$, and the aqueous phase removed carefully. Precipitation of RNA was achieved with the addition of ethanol (Deacon Laboratories Inc., King of Prussia, PA), and the subsequent RNA pellet was washed and cleaned using miRNeasy mini spin columns (Qiagen). Genomic DNA was removed during purification with on-column DNase digestion (Qiagen). RNA concentration was measured using a NanoDrop ND-1000 spectrophotometer (NanoDrop Technologies, Wilmington, DE), and RNA quality was assessed using a 2100 Bioanalyzer (Agilent Technologies, Santa Clara, CA). All samples had an RNA integrity value greater than 8.0.

$c D N A$ Synthesis and $q P C R$. Genes selected for transcript profiling in PMN were associated with cytokine production (IL1B, IL10, IL6, TNF), pattern recognition (CXCR1, JSP.1, SELL, TLR2, TLR4), inflammatory-related nuclear receptors (IRAK1, NFKB1, NR3C1), pathogen-killing mechanisms ( $L Y Z$, $M P O, S O D 1$ ), and the glutathione pathway (GPX1, GSR, DNMT3A, MAT1A, SAHH). Information regarding gene function and primers sequences can be found elsewhere (Abdelmegeid et al., 2017). A portion of the RNA was diluted to $100 \mathrm{mg} / \mathrm{L}$ using nucleasefree water before reverse transcription. We synthesized cDNA using $100 \mathrm{ng}$ of RNA, $1 \mu \mathrm{g}$ of dT18 (Operon Biotechnologies, Huntsville, AL), $1 \mu \mathrm{L}$ of $10 \mathrm{mmol} / \mathrm{L}$ dNTP mix (Invitrogen, Carlsbad, CA), $1 \mu \mathrm{L}$ of random primers (Invitrogen), and $10 \mu \mathrm{L}$ of nuclease-free water. The mixture was incubated at $65^{\circ} \mathrm{C}$ for $5 \mathrm{~min}$ and kept on ice for $3 \mathrm{~min}$. A total of $6 \mu \mathrm{L}$ of master mix composed of $4.5 \mu \mathrm{L}$ of $5 \times$ First-Strand Buffer, 1 $\mu \mathrm{L}$ of $0.1 \mathrm{M}$ DTT, $0.25 \mu \mathrm{L}(50 \mathrm{U})$ of SuperScript III RT (Invitrogen), and $0.25 \mu \mathrm{L}$ of RNase Inhibitor (10 U, Promega, Madison, WI) was added. The reaction was performed in an Eppendorf (Hamburg, Germany) Mastercycler Gradient using the following temperature program: $25^{\circ} \mathrm{C}$ for $5 \mathrm{~min}, 50^{\circ} \mathrm{C}$ for $60 \mathrm{~min}$, and $70^{\circ} \mathrm{C}$ for $15 \mathrm{~min}$. The cDNA was then diluted 1:4 (vol/vol) with nuclease-free water.

Quantitative PCR (qPCR) was performed using 4 $\mu \mathrm{L}$ diluted cDNA combined with $6 \mu \mathrm{L}$ of a mixture composed of $5 \mu \mathrm{L}$ SYBR Green master mix (Applied Biosystems, Waltham, MA), $0.4 \mu \mathrm{L}$ each of $10 \mu M$ forward and reverse primers, and $0.2 \mu \mathrm{L}$ of nucleasefree water in a MicroAmp Optical 384-Well Reaction Plate (Applied Biosystems). Each sample was run in triplicate, and a 6-point relative standard curve plus the non-template control were used. The reactions were performed in an ABI Prism 7900 HT SDS instrument (Applied Biosystems), using the following conditions: 2 min at $50^{\circ} \mathrm{C}, 10 \mathrm{~min}$ at $95^{\circ} \mathrm{C}, 40$ cycles of $15 \mathrm{~s}$ at $95^{\circ} \mathrm{C}$ (denaturation), and $1 \mathrm{~min}$ at $60^{\circ} \mathrm{C}$ (annealing + extension). The presence of a single PCR product was verified by the dissociation protocol, using incremental temperatures to $95^{\circ} \mathrm{C}$ for $15 \mathrm{~s}$ plus $65^{\circ} \mathrm{C}$ for $15 \mathrm{~s}$. Data were calculated with the 7900 HT Sequence Detection Systems Software (version 2.2.1, Applied Biosystems). The final data were normalized using the geometric mean of 3 internal control genes: GAPDH, RPS9, and UXT. Details of the qPCR performance can be found in Supplemental Table S4 (https://doi.org/10.3168/jds .2018-15737).

\section{Statistical Analysis}

After normalization with the geometric mean of the internal control genes, the triplicate averages of the qPCR data were $\log _{2}$ transformed before statistical analysis, to obtain a normal distribution. The incubation tubes were treated as individual observations. Statistical analysis was performed with SAS. Normalized, $\log _{2}$ transformed data were subjected to ANOVA with PROC MIXED. Normality of the residuals was tested via PROC UNIVARIATE in SAS. All observations were normally distributed. The statistical model included L:M ratio (3.6:1, 2.9:1, 2.4:1), LPS stimulation (yes, no), and their interactions (L:M $\times$ LPS) as fixed effects. The Kenward-Roger statement was used for computing the denominator degrees of freedom. Orthogonal contrasts were used to determine the linear or quadratic effect of L:M overall, or within LPS levels. Data were considered significant at $P \leq 0.05$, using the PDIFF statement in SAS. For ease of interpretation, 
VAILATI-RIBONI ET AL.

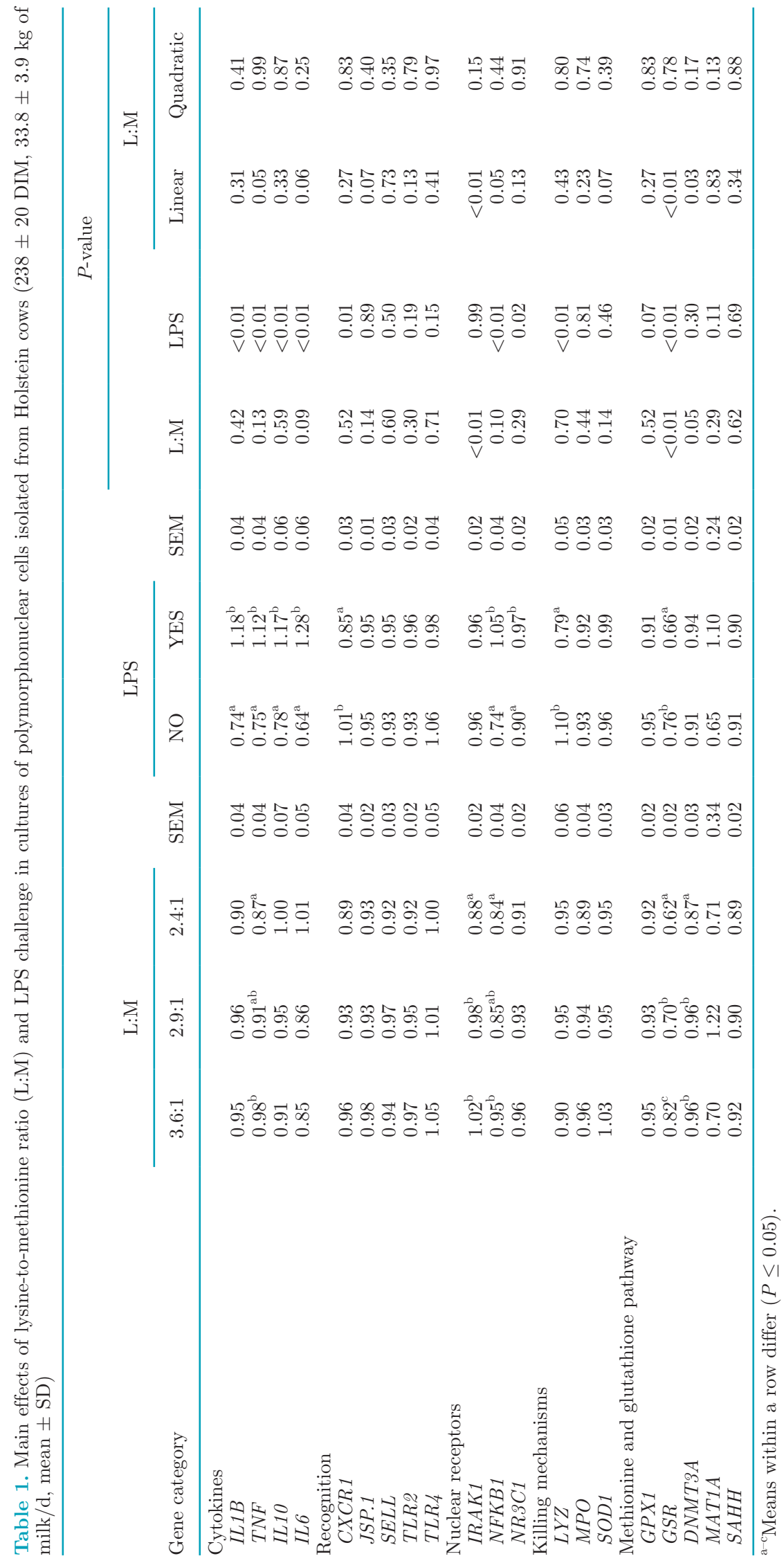




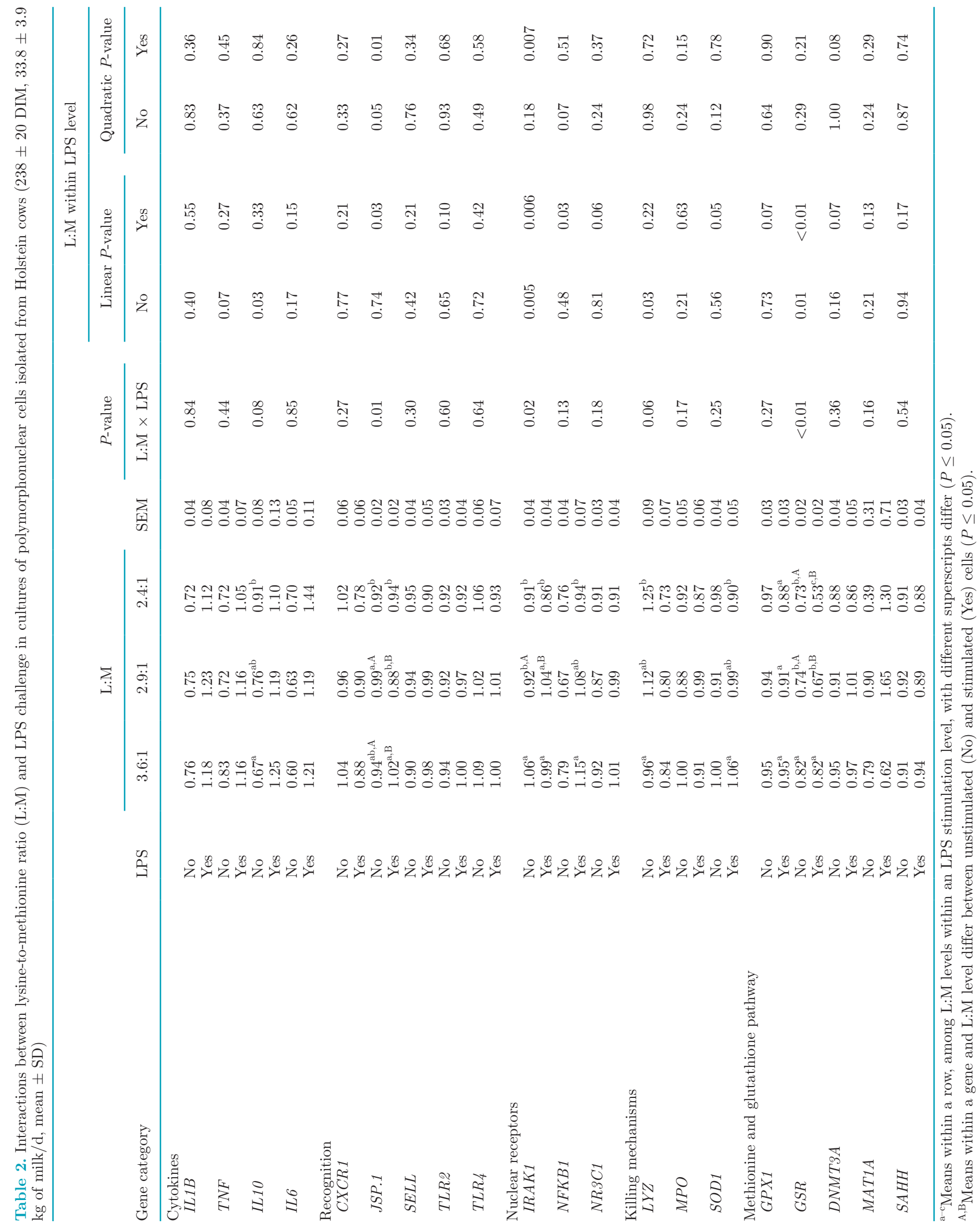


estimates and standard errors reported in Tables 1 and 2 were properly back-transformed.

\section{RESULTS}

\section{LPS Effect}

The main effect of LPS challenge on blood PMN gene expression is reported in Table 1. LPS stimulation induced an increase $(P<0.05)$ in all cytokine mRNA expression (IL1B, TNF, IL10, and IL6). However, the expression of genes related to pattern recognition (TLR2 and TLR4), PMN adhesion (SELL), or antigen presentation (JSP.1) were not changed by LPS challenge. The expression of the interleukin- 8 receptor CXCR 1 was downregulated $(P<0.05)$ in PMN stimulated with LPS. Among the nuclear receptors, both NFKB1 and NR3C1, but not IRAK1, were upregulated $(P<0.05)$ in the LPS-challenged group. In addition, the expression of $M P O$ and $S O D 1$ were unchanged $(P$ $>0.05$ ) by stimulating PMN with LPS, whereas $L Y Z$ expression was downregulated in the LPS groups $(P<$ 0.05). Among the targeted genes related to Met and glutathione pathways, only GSR mRNA expression was markedly decreased in LPS-stimulated PMN $(P$ $<0.05)$.

\section{Methionine Effect}

A linear decrease $(P<0.05)$ was observed in the mRNA expression of TNF when the ratio of L:M decreased (i.e., when Met supply increased). Similarly, IRAK1 and NFKB1 had a linear decrease $(P<0.05)$ as L:M decreased. Among the genes related to Met and glutathione pathway, GSR and DNMT3A were affected by the L:M ratio, with a linear decrease $(P<0.05)$ of their mRNA expression as L:M decreased.

\section{Interactions Between Methionine and LPS}

Results for the interaction of L:M ratio with LPS challenge are reported in Table 2. When the L:M ratio decreased without exogenous LPS there was a linear increase $(P<0.05)$ for IL10 mRNA expression. However, when stimulated with LPS, this response was not observed $(P>0.05)$. Expression of JSP.1 responded quadratically to the decrease of L:M ratio both with and without LPS challenge $(P<0.05)$. In contrast, in unstimulated samples the response was opposite, with L:M ratio of 2.9:1 causing the highest expression, whereas it caused the lowest response when LPS was added. This led to a significant $(P<0.05)$ interaction between L:M and LPS, with a higher JSP.1 mRNA ex- pression in stimulated samples at an L:M ratio of 3.6:1, and a lower expression in stimulated versus unstimulated samples when L:M ratio was 2.9:1. No differences $(P>0.05)$ were observed at the highest L:M ratio of 2.4:1. In addition, no interactions $(P>0.05)$ between L:M and LPS were detected for other genes related to pathogen recognition, including CXCR1, SELL, TLR2, and TLR4.

The expression of IRAK1 decreased linearly $(P<$ $0.05)$ as L:M ratio decreased in PMN treated both with and without LPS, with lowest abundance for IRAK1 mRNA observed at L:M ratio of 2.4:1. Furthermore, an interaction of L:M ratio and LPS challenge was also observed as a result of higher $(P<0.05)$ mRNA expression of IRAK1 at L:M of 2.9:1 in PMN treated with LPS. The transcription factor NFKB1 was linearly decreased $(P<0.05)$ as the L:M ratio decreased in LPS-challenged PMN cells but not in the unchallenged PMN.

Among the genes related to killing mechanisms, a linear increase of $L Y Z$ mRNA expression was found in unstimulated PMN as L:M ratio decreased $(P<0.05)$, causing higher expression in unstimulated PMN at both L:M of 2.9:1 and 2.4:1 compared with LPS-challenged PMN $(P<0.05)$. Furthermore, the decrease in L:M ratio led to a linear decrease of SOD1 mRNA expression in challenged but not in the unchallenged PMN.

Concerning Met and glutathione metabolism, no interactions $(P>0.05)$ were detected for the expression of GPX1, DNMT3A, MAT1A, or SAHH mRNA. However, a linear effect of L:M ratio was detected for GSR expression in both stimulated and unstimulated PMN. This also led to an interaction between L:M ratio and LPS, with lower expression of GSR in stimulated PMN supplemented with Met to reach L:M ratios of 2.9:1 and 2.4:1.

\section{DISCUSSION}

Lactating dairy cows are typically supplemented with additional Met to reach an L:M ratio of 3:1 in the MP, as this relationship has been determined to be optimal for milk protein synthesis. Our choices of L:M ratios of 3.6:1, 2.9:1, and 2.4:1 for incubations represent levels obtained in typical corn silage-based diets not supplemented with rumen-protected Met, diets supplemented with rumen-protected Met to reach an approximately 3:1 ratio, and diets supplemented with additional Met to push the current industry standard, respectively. We surmise that additional Met would provide the cow with spare Met for other physiological functions, such as the immune response. 


\section{Effects of Methionine Supplementation}

We recently reported the effect of Met supplementation in vivo on circulating PMN gene expression. Those results indicated an overall lower degree of activation, better redox status, and improved response upon challenge (Zhou et al., 2018). The present in vitro experiment confirmed those previous responses. The overall linear downregulation in TNF, IRAK1, NFKB1, GSR, and DNMT3A, together with the linear upregulation of the anti-inflammatory cytokine $I L 10$, suggested a lower activation stage of PMN (Moyes et al., 2010) and a better redox status as Met supply increased. At the same time the upregulation of JSP.1, a component of the antigen presenting mechanism, and $L Y Z$, a key antimicrobial enzyme in the PMN arsenal, seems to highlight a priming effect of Met on the capacity of these cells to respond readily upon stimulation.

The downregulation of antigen-presenting mechanisms (JSP.1) and regulatory receptors (NFKB1 and IRAK1) when PMN were stimulated with LPS at the lower L:M ratio (i.e., higher levels of Met) suggested a diminished response to pathogens ( $\mathrm{Li}$ et al., 2015). These data are somewhat opposite to our previous results highlighting how both PMN and monocytes from cows supplemented with Met had greater phagocytosis capacity and oxidative burst response when challenged ex vivo with E. coli (Osorio et al., 2013; Zhou et al., 2016b; Vailati-Riboni et al., 2017). In the current experiment, isolated PMN were stimulated with LPS for $2 \mathrm{~h}$ to determine how increasing Met supply could elicit effects during the activation stage of the cells. However, a previous report indicated a very rapid PMN response, on the order of minutes, to LPS stimulation, with maximum release of superoxide anions $\left(\mathrm{O}_{2}{ }^{-}\right)$within 15 to 60 min of stimulation and return to pre-challenge levels within $2 \mathrm{~h}$ (Aida and Pabst, 1991). Thus, we believe that our results more closely resemble the control stages of the inflammatory process, during the resolution stage of the PMN response.

The observed interactions between Met supply and LPS stimulation suggest better control and resolution of the inflammatory response when Met increases. A similar optimization and control of the inflammatory response was observed previously ex vivo (VailatiRiboni et al., 2017). To corroborate this hypothesis, despite the lack of actual data, the downregulation of GSR and SOD1 suggests a lower concentration of free radicals present after $2 \mathrm{~h}$, which would indicate a faster resolution of the inflammatory response due to Met supply. Despite being considered a detrimental effect, as it leads to extended or chronic consequences in the inflammatory response, a downregulation of SOD1 expression might increase PMN life span, reducing apoptotic signals (Yasui et al., 2005).

\section{Effects of LPS Stimulation}

Lipopolysaccharide, the major endotoxin of gramnegative bacteria, is recognized to be a major mediator of immune cell activation, PMN included (Guthrie et al., 1984; Doerfler et al., 1989; Aida and Pabst, 1991). Hence, upregulation of the transcription factor NFKB1, along with the pro-inflammatory cytokines $I L 1 B, I L 6$, and $T N F$ in the present study upon stimulation with LPS, agreed with previous data (Hayden and Ghosh, 2011) and underscored that the dose and timing of the challenge were adequate to obtain a response in the freshly isolated PMN from mid-lactation dairy cows.

Despite the clear activation of PMN upon LPS challenge, data also indicate the existence of a feedback mechanism to contain the activation of PMN. After activation, in fact, PMN showed downregulation of CXCR1, the receptor for chemokine IL-8, which causes them to migrate to sites of infection (Fujishima et al., 1993; Sabroe et al., 2005), and upregulation of IL10 and NRC31, both of which have potent anti-inflammatory effects counteracting the expression of pro-inflammatory cytokines (Couper et al., 2008; Chinenov et al., 2013).

The downregulation of LYZ, encoding the antibacterial enzyme lysozyme, upon stimulation with LPS, agreed with previous data in both porcine and human peripheral blood mononuclear cells (Gao et al., 2010; Van Belleghem et al., 2017). The mechanistic reason for such effect is unknown. Previous study has shown that LPS binds to lysozyme and inhibits its activity and that, at the same time, binding reduces the endotoxicity of LPS (Ohno and Morrison, 1989). We know of no clear explanation for what seems to be a feedback regulatory mechanism of the PMN immune response to LPS.

The enzyme glutathione reductase (GSR) restores the reduced form of glutathione, an important cellular antioxidant that helps to eliminate $\mathrm{H}_{2} \mathrm{O}_{2}$ within cytosol, preventing oxidative damage to PMN (Cohen et al., 1987). Thus, the downregulation of GSR expression upon stimulation with LPS seems counterintuitive, as LPS causes PMN activation and engages the oxidative burst response. Because in GSR-deficient individuals (Roos et al., 1979) and mouse models (Yan et al., 2012) PMN immune response seems to be compromised, its downregulation would indicate a reduced functionality of the isolated PMN when challenged with LPS in our in vitro model. Despite the lack of PMN function data in the present study, previous in and ex vivo data 
demonstrated increased functionality of bovine immune cells when additional Met was added to the diet to achieve L:M ratios of approximately 3 or lower (Zhou et al., 2016b; Vailati-Riboni et al., 2017; Zhou et al., 2018). Thus, we speculate that the reduction is due to a feedback mechanism to control and resolve the inflammatory response started $2 \mathrm{~h}$ prior. These mechanisms have already been observed at the enzyme activity level and could possibly exist at the transcriptional level as well. In a matter of seconds after stimulation, GSR activity is increased to withstand the marked production of reactive oxygen species, but 30 min later activity is already reduced due to consumption of $\mathrm{H}_{2} \mathrm{O}_{2}$ by myeloperoxidase as part of the burst response (Strauss et al., 1969). The production of nitric oxide (NO) concurrently with reactive oxygen species during activation has been found to reduce GSR activity, an effect that is thought to help counterbalance the effect of $\mathrm{H}_{2} \mathrm{O}_{2}$ on the enzyme. Because cellular reduced glutathione levels decrease in parallel with NO, it has been assumed that NO regulates its own synthesis through various negative feedback mechanisms on nitric oxide synthase (NOS) activity, including the reduction of cellular reduced glutathione (Butzer et al., 1999).

\section{CONCLUSIONS}

The current data suggest that the isolation of PMN from lactating cows is a suitable model to study the effect of nutrient supplementation or inflammatory stimulation - or both - in vitro. However, we suggest a pre-incubation period and a shorter time frame of stimulation to capture the response at peak activation. From a practical standpoint, targeting the supply of Met to an L:M ratio of at least 3, but with greater benefits at 2.4:1, might improve PMN inflammatory and oxidative status. As such, in the event of stimulation, this level of Met could help the resolution of inflammation. This effect would help cows avoid a prolonged or chronic detrimental result of the inflammatory response. Future work will have to assess concurrently immune function and supernatant markers to obtain a more comprehensive understanding.

\section{ACKNOWLEDGMENTS}

T. $\mathrm{Xu}$ received a $\mathrm{PhD}$ fellowship from the China Scholarship Council (CSC; Beijing) to train at the University of Illinois at Urbana-Champaign. B. Qadir received the Iraq Biosciences Fellowship (CRDF Global, Arlington, VA) to train at the University of Illinois at Urbana-Champaign.

\section{REFERENCES}

Abdelmegeid, M. K., M. Vailati-Riboni, A. Alharthi, F. Batistel, and J. J. Loor. 2017. Supplemental methionine, choline, or taurine alter in vitro gene network expression of polymorphonuclear leukocytes from neonatal Holstein calves. J. Dairy Sci. 100:3155-3165.

Aida, Y., and M. J. Pabst. 1991. Neutrophil responses to lipopolysaccharide. Effect of adherence on triggering and priming of the respiratory burst. J. Immunol. 146:1271-1276.

Atmaca, G. 2004. Antioxidant effects of sulfur-containing amino acids. Yonsei Med. J. 45:776-788.

Batistel, F., J. M. Arroyo, A. Bellingeri, L. Wang, B. Saremi, C. Parys, E. Trevisi, F. C. Cardoso, and J. J. Loor. 2017. Ethyl-cellulose rumen-protected methionine enhances performance during the periparturient period and early lactation in Holstein dairy cows. J. Dairy Sci. 100:7455-7467. https://doi.org/10.3168/jds.2017-12689.

Batistel, F., J. M. Arroyo, C. I. M. Garces, E. Trevisi, C. Parys, M. A. Ballou, F. C. Cardoso, and J. J. Loor. 2018. Ethyl-cellulose rumen-protected methionine alleviates inflammation and oxidative stress and improves neutrophil function during the periparturient period and early lactation in Holstein dairy cows. J. Dairy Sci. 101:480-490. https://doi.org/10.3168/jds.2017-13185.

Brosnan, J. T., and M. E. Brosnan. 2006. The sulfur-containing amino acids: An overview. J. Nutr. 136:1636S-1640S.

Butzer, U., H. Weidenbach, S. Gansauge, F. Gansauge, H. G. Beger, and A. K. Nussler. 1999. Increased oxidative stress in the RAW 264.7 macrophage cell line is partially mediated via the S-nitrosothiol-induced inhibition of glutathione reductase. FEBS Lett. 445:274-278.

Chinenov, Y., R. Gupte, and I. Rogatsky. 2013. Nuclear receptors in inflammation control: Repression by GR and beyond. Mol. Cell. Endocrinol. 380:55-64.

Cohen, H. J., E. H. Tape, J. Novak, M. E. Chovaniec, P. Liegey, and J. C. Whitin. 1987. The role of glutathione reductase in maintaining human granulocyte function and sensitivity to exogenous $\mathrm{H} 2 \mathrm{O} 2$. Blood 69:493-500.

Couper, K. N., D. G. Blount, and E. M. Riley. 2008. IL-10: The master regulator of immunity to infection. J. Immunol. 180:5771-5777.

Doerfler, M. E., R. L. Danner, J. H. Shelhamer, and J. E. Parrillo. 1989. Bacterial lipopolysaccharides prime human neutrophils for enhanced production of leukotriene B4. J. Clin. Invest. 83:970-977.

Du, X., T. Shen, H. Wang, X. Qin, D. Xing, Q. Ye, Z. Shi, Z. Fang, Y. Zhu, Y. Yang, Z. Peng, C. Zhao, B. Lv, X. Li, G. Liu, and X. Li. 2018. Adaptations of hepatic lipid metabolism and mitochondria in dairy cows with mild fatty liver. J. Dairy Sci. 101:9544-9558. https://doi.org/10.3168/jds.2018-14546.

Fujishima, S., A. R. Hoffman, T. Vu, K. J. Kim, H. Zheng, D. Daniel, Y. Kim, E. F. Wallace, J. W. Larrick, and T. A. Raffin. 1993. Regulation of neutrophil interleukin 8 gene expression and protein secretion by LPS, TNF-alpha, and IL-1 beta. J. Cell. Physiol. 154:478-485.

Gao, Y., L. Flori, J. Lecardonnel, D. Esquerre, Z. L. Hu, A. Teillaud, G. Lemonnier, F. Lefevre, I. P. Oswald, and C. Rogel-Gaillard. 2010. Transcriptome analysis of porcine PBMCs after in vitro stimulation by LPS or PMA/ionomycin using an expression array targeting the pig immune response. BMC Genomics 11:292.

Grimble, R. F. 2006. The effects of sulfur amino acid intake on immune function in humans. J. Nutr. 136:1660S-1665S.

Grimble, R. F., and G. K. Grimble. 1998. Immunonutrition: Role of sulfur amino acids, related amino acids, and polyamines. Nutrition 14:605-610.

Guthrie, L. A., L. C. McPhail, P. M. Henson, and R. B. Johnston Jr.. 1984. Priming of neutrophils for enhanced release of oxygen metabolites by bacterial lipopolysaccharide. Evidence for increased activity of the superoxide-producing enzyme. J. Exp. Med. 160:1656-1671.

Hayden, M. S., and S. Ghosh. 2011. NF-kappaB in immunobiology. Cell Res. 21:223-244.

Li, P., Y. L. Yin, D. Li, S. W. Kim, and G. Wu. 2007. Amino acids and immune function. Br. J. Nutr. 98:237-252. 
Li, X., W. Huang, J. Gu, X. Du, L. Lei, X. Yuan, G. Sun, Z. Wang, X. Li, and G. Liu. 2015. SREBP-1c overactivates ROS-mediated hepatic NF- $\kappa B$ inflammatory pathway in dairy cows with fatty liver. Cell. Signal. 27:2099-2109. https://doi.org/10.1016/j.cellsig .2015.07.011.

Loor, J. J., M. Bionaz, and J. K. Drackley. 2013. Systems physiology in dairy cattle: Nutritional genomics and beyond. Annu. Rev. Anim. Biosci. 1:365-392. https://doi.org/10.1146/annurev-animal $-031412-103728$

Marczuk, J., P. Brodzki, A. Brodzki, and L. Kurek. 2018. The concentration of free amino acids in blood serum of dairy cows with primary ketosis. Pol. J. Vet. Sci. 21:149-156.

Martinov, M. V., V. M. Vitvitsky, R. Banerjee, and F. I. Ataullakhanov. 2010. The logic of the hepatic methionine metabolic cycle. Biochim. Biophys. Acta 1804:89-96.

Moyes, K. M., J. K. Drackley, D. E. Morin, and J. J. Loor. 2010. Greater expression of TLR2, TLR4, and IL6 due to negative energy balance is associated with lower expression of HLA-DRA and HLA-A in bovine blood neutrophils after intramammary mastitis challenge with Streptococcus uberis. Funct. Integr. Genomics 10:53-61. https://doi.org/10.1007/s10142-009-0154-7.

National Research Council. 2001. Nutrient Requirements of Dairy Cattle. 7th rev. ed. Natl. Acad. Press, Washington, DC.

Ohno, N., and D. C. Morrison. 1989. Lipopolysaccharide interaction with lysozyme. Binding of lipopolysaccharide to lysozyme and inhibition of lysozyme enzymatic activity. J. Biol. Chem. 264:44344441.

Osorio, J. S., P. Ji, J. K. Drackley, D. Luchini, and J. J. Loor. 2013. Supplemental Smartamine M or MetaSmart during the transition period benefits postpartal cow performance and blood neutrophil function. J. Dairy Sci. 96:6248-6263.

Redmond, H. P., P. P. Stapleton, P. Neary, and D. Bouchier-Hayes 1998. Immunonutrition: The role of taurine. Nutrition 14:599-604

Rogers, J. A., U. Krishnamoorthy, and C. J. Sniffen. 1987. Plasma amino acids and milk protein production by cows fed rumen-protected methionine and lysine. J. Dairy Sci. 70:789-798.

Roos, D., R. S. Weening, A. A. Voetman, M. L. van Schaik, A. A. Bot, L. J. Meerhof, and J. A. Loos. 1979. Protection of phagocytic leukocytes by endogenous glutathione: Studies in a family with glutathione reductase deficiency. Blood 53:851-866.

Sabroe, I., E. C. Jones, M. K. Whyte, and S. K. Dower. 2005. Regulation of human neutrophil chemokine receptor expression and function by activation of Toll-like receptors 2 and 4 . Immunology 115:90-98.

Sadri, H., D. von Soosten, U. Meyer, J. Kluess, S. Danicke, B. Saremi, and H. Sauerwein. 2017. Plasma amino acids and metabolic pro- filing of dairy cows in response to a bolus duodenal infusion of leucine. PLoS One 12:e0176647.

Strauss, R. R., B. B. Paul, A. A. Jacobs, and A. J. Sbarra. 1969. The role of the phagocyte in host-parasite interactions. XIX. Leukocytic glutathione reductase and its involvement in phagocytosis. Arch. Biochem. Biophys. 135:265-271.

Vailati-Riboni, M., Z. Zhou, C. B. Jacometo, A. Minuti, E. Trevisi, D. N. Luchini, and J. J. Loor. 2017. Supplementation with rumenprotected methionine or choline during the transition period influences whole-blood immune response in periparturient dairy cows. J. Dairy Sci. 100:3958-3968.

Van Belleghem, J. D., F. Clement, M. Merabishvili, R. Lavigne, and M. Vaneechoutte. 2017. Pro- and anti-inflammatory responses of peripheral blood mononuclear cells induced by Staphylococcus aureus and Pseudomonas aeruginosa phages. Sci. Rep. 7:8004.

Verbeke, R., E. Roets, and G. Peeters. 1972. Variations in the concentrations of free amino acids in the plasma of the dairy cow at parturition. J. Dairy Res. 39:355-364.

Yan, J., X. Meng, L. M. Wancket, K. Lintner, L. D. Nelin, B. Chen, K. P. Francis, C. V. Smith, L. K. Rogers, and Y. Liu. 2012. Glutathione reductase facilitates host defense by sustaining phagocytic oxidative burst and promoting the development of neutrophil extracellular traps. J. Immunol. 188:2316-2327.

Yasui, K., N. Kobayashi, T. Yamazaki, K. Agematsu, S. Matsuzaki, S. Ito, S. Nakata, A. Baba, and K. Koike. 2005. Superoxide dismutase (SOD) as a potential inhibitory mediator of inflammation via neutrophil apoptosis. Free Radic. Res. 39:755-762.

Zhou, Z., F. Ferdous, P. Montagner, D. N. Luchini, M. N. Correa, and J. J. Loor. 2018. Methionine and choline supply during the peripartal period alter polymorphonuclear leukocyte immune response and immunometabolic gene expression in Holstein cows. J. Dairy Sci. 101:10374-10382.

Zhou, Z., M. Vailati-Riboni, D. N. Luchini, and J. J. Loor. 2016a. Methionine and choline supply during the periparturient period alter plasma amino acid and one-carbon metabolism profiles to various extents: potential role in hepatic metabolism and antioxidant status. Nutrients 9:E10.

Zhou, Z., M. Vailati-Riboni, E. Trevisi, J. K. Drackley, D. N. Luchini, and J. J. Loor. 2016b. Better postpartal performance in dairy cows supplemented with rumen-protected methionine compared with choline during the peripartal period. J. Dairy Sci. 99:8716-8732.

Zhu, Y., G. Liu, X. Du, Z. Shi, M. Jin, X. Sha, X. Li, Z. Wang, and X. Li. 2019. Expression patterns of hepatic genes involved in lipid metabolism in cows with subclinical or clinical ketosis. J. Dairy Sci. 102:1725-1735. https://doi.org/10.3168/jds.2018-14965. 